assembly, inspection and moderately heavy lifting, were papers by R. McKenzie (University of Edinburgh) showing how greatly performance of inspection work can be improved by suitable training, and by R. J. Whitney (University of Oxford) indicating that lifting force depends more upon the possibility of balancing the weight to be lifted with the weight of the body than upon sheer muscular power.

Viewing the papers as a whole, one can see that the application of anatomy, physiology and experimental psychology to practical problems of human work has reached a critical stage. During the later 1940's success had been achieved with Service problems and ideas of possible industrial application were being formulated. Now world-wide interest has been aroused, concrete examples of industrial application are beginning to emerge, and the approach seems likely to become established as an essential part of work- and equipment-design. For it to do so fully, however, much further research will be needed both in industry itself and in the laboratory. In this connexion two sessions a little away from the main lines of the conference were timely. The first was a discussion opened by R. G. Stansfield (Department of Industrial and Scientific Research) on the moral responsibilities of the research worker in industry, especially in cases when it is necessary for the true nature of the investigation to be disguised if the results are to be unbiased: stress was laid on the need to give full information to representatives of the work-people concerned, and to preserve secrecy of data about individuals. At the second session an account was given by R. M. W. Lund and R. Trumbull (Office of Naval Research, Washington) of the means employed by the United States Navy to sponsor ite very large physiological and psychological research programmes. The realistic appraisal of the needs and motives of research workers, and the recognition of the place of fundamental research in relation to applied problems revealed in these statements, makes understandable the substantial volume of high-quality work which has emerged.

While the methods of sponsoring research are obviously important, a limiting factor in the immediate future is likely to lie in the obtaining of suitable research workers and in their attitude to their work. Looking back to the war years it is clear that the success achieved then in what has now become known as 'ergonomics' was due to two factors: first, an analytical approach to complex problems coupled with careful measurement, and secondly, the wide theoretical background brought by the research workers from their own disciplines. Since that time the former seems to have been well maintained, but both are equally important and for the preservation of the latter there are two constant needs. The first is to recognize that applicable results usually follow a long period of research development. The second is to maintain a climate of opinion in which a young man engaged in the human biological sciences cen feel that serious attempts to tackle certain applied problems will improve rather than impair his chances of academic advancement, and will certainly enrich the ideas he brings to the fundamental problems of his own subject.

The conference was attended by some ninety-five members and visitors of whom twenty-one came from eight countries abroad. The chair at the opening session was taken by Sir Philip Morris, vice-chancellor of the University of Bristol.

\section{DEVELOPMENTAL PROCESSES IN ANIMALS}

$T$ HE third in the series of international scientific meetings sponsored by the Editorial Board of the Journal of Embryology and Experimental Morphology was held in Cambridge during April 10-13. Some one hundred and fifty biologists from sixteen countries took part, and only the failure of the expected Russian participants to arrive gave any ground for disappointment at the international representation at the conference.

It is probably true to say that the session devoted to demonstrations of research material, at which more than forty lines of work were displayed, provided the most comprehensive survey of present trends in developmental biology. None the less the main business of the conference was conducted in the sessions at which papers were read, and in them many of the major interests of contemporary embryology were presented for discussion.

The recrudescence of concern with the problems of neural induction in vertebrates was very evident. Thus Dr. P. D. Nieuwkoop (Utrecht) produced evidence, from explantation experiments, for believing that the amphibian neural crest is determined by a double process, an initial activation being succeeded by a transforming influence from the underlying mesoderm. He pointed out that the anterior, transverse, part of the neural fold of the neurula normally lies in front of the pre-chordal mesoderm and is underlain by endoderm. It does not give rise to neural crest derivatives in normogenesis or when cultured with ectoderm alone, but they may be formed from its cells if it is cultured in the presence of mesoderm.

Prof. T. Yamada (Nagoya) has inade important progress in the effort to isolate the components of guinea pig liver and kidney responsible for their regionally specific inductive effects upon competent amphibian ectoderm. His results point very strongly to the protein part of pentose nucleoproteins as the active fraction, though it has not been possible to exclude with certainty the lipids or pentose nucleic acid itself. Heat treatment of alcohol-killed bonemarrow progressively changes the regional character of the structures it will induce. Unheated, it is a specific inducer of mesodermal structures, but after heat treatment (by steaming), first spinal and then, with increase in the duration of treatment, hind brain and finally fore brain inductions are obtained. This sequence is also the spatial sequence of the presumptive territories of these tissues in the blastula.

Miss M. Brice (Brussels) reported on the consequences of dividing urodele blastulæ and young gastrulæ into two by ligature. Contrary to our earlier beliefs, an isolated ventral half-embryo may sometimes form a centre of invagination and later an embryonic axis. The formation of such secondary 'dorsal lips' appears to be associated with the local trauma involved in ligaturing. Where embryos are formed their polarity and symmetry may be reversed. In the young gastrula it is still possible to obtain a new marginal zone, nor can the symmetry of the germ be regarded as fully determined.

The sites of protein synthesis during early embryogenesis in birds and Amphibia have been studied by Prof. C. H. Waddington (Edinburgh) by the autoradiographic location of labelled amino-acids. Glycine 
and methionine are first incorporated in the nuclei of the dorsal lip material of the amphibian embryo. Later, radioactivity is found in ever more extensive regions of the embryo. Adenine is incorporated mainly at the margins of nucleoli. Some time after nuclear incorporation can be demonstrated labelled. material is found in the cytoplasm. During embryonic induction there is good evidence that labelled molecules pass from the nuclei of the inducer into the cytoplasm of the cells of the responding tissue.

Dr. A. Ficq (Brussels) has studied the incorporation of labelled amino-acids in the oocytes of amphibians at different stages of their growth. In Rana, Pleurodeles and Triturus she has been able to demonstrate that adenosine triphosphate and purine bases are synthesized during the period of oocyte growth, adenine being incorporated into the adenosine triphosphate fraction. Glycine is taken up especially actively in the basophilic regions of the cytoplasm and it is here that protein synthesis is proceeding in the period of yolk formation.

Several workers described analyses of tissue interactions occurring long after primary embryogenesis. Thus Dr. P. Sengel (Paris) has made an in vitro study of the development of the saddle tract feathers of White Leghorn embryos. Saddle tract skin taken from five-day embryos will not form feathers when cultured alone, though a variety of tissues, alive or dead, may induce it to do so. Skin from six- or seven-day embryos will form feathers, but only after regulative adaptation of their spatial distribution to the geography of the explant. The established feather germs from seven- or eight-day embryos continue their normal development in explants. Dr. Sengel has also shown that an early influence of dermis upon epidermis and a subsequent reciprocal influence of epidermis upon dermis are essential for feather formation.

Prof. G. V. Lopashov (Moscow), in a paper read for him in his absence, reviewed a series of researches into the factors controlling the later development of the amphibian eye. Among the more important factors analysed were the mechanical limitations to the 'spreading' of the optic vesicle material, the influence of the mesenchymal sheath of the eyeball, its vascularization and other contacts with body fluids, and with the lens ectoderm.

Prof. Et. C. Wolff (Paris) has examined the leg-bud of the embryo chick for its capacity to regulate after the loss of parts and after the addition of extra material. Regulation after defects is good, although the fibula-normally, of course, semi-vestigial-may disappear altogether. Regulation of limb systems containing additional material, for example, a whole, younger, limb-bud, is also achieved, but in these cases the fibula may be well formed, a condition not known to have occurred in normal birds since Archaeopteryx and Archaeornis of Jurassic times. It appears that the normal development of the lower leg involves competition for material between tibia and fibula and that the tibia dominates except in the presence of excess.

Dr. P. Tschumi (Cambridge) revealed hitherto unsuspected similarities between the mode of development of the amphibian limb, or at least the hind-limb, of Xenopus, and that of birds. Not only is the growth of the limb-bud achieved by apical proliferation, but the pattern of differentiation within it is under the influence of an ectodermal ridge running in a pre-axial-post-axial direction along its distal margin. There is evidence that a marginal vein underlying this ridge is not only produced under its influence but is also responsible for mediating its control of the limb mesoderm.

In a theoretical consideration of the problem of reversible and irreversible changes in the nuclei of somatic cells during differentiation, Dr. M. Fischberg (Oxford) pointed out that there is increasing evidence for the occurrence of irreversible nuclear changes. These may also appear in clones of Protozoa. He suggested that, in the course of the often considerable number of chromosome replications neces. sary to turn an egg into a metazoan adult, it was possible that specific precursors for particular gene replications might become exhausted in cells of particular types. Thus, by a sort of selective gene starvation, the effective nuclear constitution of different cells in the body might come to diverge.

Prof. J. F. Danielli (London) was also concerned with events at the level of the cell. He proposed $\varepsilon_{0}$ scheme for the minimum requirements of controlling systems for the maintenance of the living cell and for its division, and discussed the extent to which we could be said at the present time to have discovered the keys to their understanding. While we have, in principle, some conception of the control of the specificity of molecules elaborated in the cell, and of their relative proportions and interactions within it, we had still to get to terms with the problem presented by organization of intra-cellular structure. $\mathrm{H} \theta$ suggested that the centres of crystallization in super-saturated solutions might have analogues serving as sources of information for the elaboration of intra-cellular structure.

Dr. P. Tuft (Edinburgh) has studied the water relations of the embryo of Xenopus from pre-blastula stages through to hatching. He has shown that the well-known hydration of amphibian embryos in their early life is not a simple result of uptake of water into their cells. On the contrary, most of the water absorbed by the whole young embryo passes through the surface cells into the embryonic cavities-both blastocœle and archenteron. Only after the collapse of the archenteron does much water accumulate in the cells. Accumulation is throughout less rapid than one would predict from the osmotic gradients and surface permeability. Although the gradient decreases and the permeability remains constant the rate of accumulation goes up, indicating that the water movement is actively controlled.

Prof. Z. Grodzinski (Krakow) reviewed an extensive series of observations on the heart of embryonic teleosts. An early phase of peristaltic contraction is followed by systolic function under the control of pacemakers in the auricle and ventricle. A supernumerary pacemaker exists in the ventricle which is not represented in the adult heart. The efficiency of cardiac muscle is shown to increase with time, and the embryonic heart proves to be a remarkably accurate thermometer, the pulse-rate varying in linear manner with temperature over a wide range.

Dr. L. Saxén (Helsinki) presented an account of the function of the pituitary and thyroid in Xenopus during larval life and metamorphosis. Histological examination of the pituitary and histological and chemical studies of thyroid colloid combine to give a consistent picture of events. The colloid content of the thyroid drops sharply during metamorphosis, although in the pre-metamorphic period iodine is being accumulated there. After metamorphosis there is a rise in thyroid iodine, followed by a secondary fall. These phases of thyroid activity correspond to 
changes in nuclear size and cytoplasmic appearance in the periodic acid-Schiff-positive cells in the pituitary which elaborate thyrotrophic hormone.

Regeneration in amphibians was the subject of two reports. Prof. F. E. Lehmann (Bern) reviewed a large body of work on the effects of substances inhibiting regeneration in the anuran tail. Many substances, including amino-acid analogues and colchicine, inhibit regeneration without causing cell death. Not all, however, are effective at all periods of the regeneration process. Thus colchicine is only effective during the period immediately following amputation, aminoketones act in the middle phase of blastema formation, and imino-benzo-quinones affect the later phase of growth and differentiation. Cathep. sin activity normally rises during early regeneration, to reach a peak after about seven days; this peak may occur later in the presence of certain inhibitors. E. M. Deuchar has shown that cathepsin activity rises in both blastema and stump, although it is higher in the former than the latter.

Dr. D. R. Newth (London) reported that urodele and anuran larvæ, with tails made defective by the earlier removal of presumptive tail material, could none the less regenerate normal tails where the plane of amputation lay proximal to the defective region. Where the plane of amputation passed through a part of the tail lacking dorsal or ventral fin the regenerate lacked the appropriate fin. Supernumerary limbs induced in urodele larvæ by nasal placode were frequently hyper- or hypo-dactylous. On amputation they tended to be replaced by more nearly normal limbs, although the restoration of normality might require a further amputation and regeneration.

The conference owed everything to the presence of so many participants from outside Great Britain. British embryologists, in particular, have reason to be grateful to the help given by the Wellcome Trust, the Science Council of Japan and the British Council in making the attendance of many of their foreign colleagues possible. The conference as a whole was indebted to the Royal Society for financial aid.

D. R. NEwTH

\section{LABORATORY ANIMALS BUREAU CONGRESS}

$\mathrm{E}^{\mathrm{A}}$ ACH year for the past decade the Laboratory Animals Bureau has organized a congress of animal and laboratory technicians. This year the congress, which since 1950 has been a two-day affair, was held in Edinburgh during April 4-5 at the Royal (Dick) School of Veterinary Studies. More than two hundred technicians from all parts of Great Britain and Northern Ireland were present, providing a record attendance.

Prof. J. H. Gaddum opened the congress. $\mathrm{He}$ directed attention to the vital part played by the animal technician in the research team and deplored the tendency in some quarters for technicians to call themselves technologists. Technologists were a different type of person, not necessarily a superior type. The technician, and in this particular context, the animal technician, had his own place and dignity.

As is usual at these congresses, all the papers but one were presented by technicians. Mr. C. R. Kennedy spoke of the uses of animals in toxicology, especially of some of the practical problems involved. It is refreshing for those whose work involves use of animals, but who are not often called upon to give the physical day-to-day care that animals demand, to know what the experiment looks like when seen from the animal room. Unsuspected details of husbandry, nearly always taken for granted by the experimenter, become matters of considerable importance and even significant sources of variation in experimental procedures.

Mr. F. Hoyland, speaking on the care and health of guinea pigs, demonstrated from the records of his own laboratory the substantial economies that can be effected, first, by the choice of healthy - in this case accredited-guinea pigs and, secondly, by a high standard of care both before and during experimental treatment. Mr. Ian Samuel, of the Moredun Institute, ranged over the wide field of tolerated infections in laboratory animals. A cursory acquaintance with this problem is sufficient to show that the demand for 'infection-free' animals is seldom, if ever, likely to be met, short of using germ-free animals, which introduces problems of its own. A more useful conception, which has been gaining ground in Britain and receiving particular attention in the United States, is that of the 'specific-pathogen-free' animal (to borrow the American phrase). Most experimenters are not really interested in being assured that their animals are free from all possible pathogens, but most of them want to be assured that no pathogens which can cause intercurrent losses are present in thoir stock, and some want to go a little further and make sure that their animals are free of certain other infections which might interfere specifically with their own work.

On the second morning, Mr. R. J. C. Stewart gave a largely reminiscent paper on the dog's place in medical research, bringing back to life some memories of the late Sir Edward Mellanby. Mr. D. L. MeLean, reporting on the incidence of cedema in the young guinea pig, described work being done in Aberdeen on this condition in guinea pigs that has been seen in recent years and has so far kept its etiology a close secret. It appears that epidemic oedema may be due to soil contamination of the grass meal used in a particular diet always associated with this condition. Mr. G. K. A. Smith produced some data of his own about the blood picture in common laboratory rodents. Finally, Dr. H. E. Lewis gave a review of alimentation in a number of common laboratory species.

On the afternoon of the first day, visits were paid to the Moredun Institute and the Veterinary Laboratory at Lasswade; and to the Small Animal Breeding Station and the Institute of Animal Genetics at the University of Edinburgh. On the second afternoon a visit was arranged to the Zoological Park.

There are two things worth noting about these congresses. The first is that about the same number of technicians, a little more than two hundred, come year after year. Since most of them have their fares and subsistence paid by their employers, it must be presumed that their employers regard their attendance as of some value. 'The second point is that each year new speakers among the technicians are found to present papers, but the standard of papers shows no tendency whatever to fall; an indication of the talent, to a large extent latent, among animal technicians. No other country in the world has meetings of this kind, meetings which belong peculiarly to the 